\title{
Iterative and asymptomatic hypophosphataemia after administration of ferric carboxymaltose in a patient undergoing with bariatric surgery
}

\begin{abstract}
Context: Hypophosphataemia after administration of ferric carboxymaltose (FeCXM), secondary to

excessive urinary phosphate loss mediated by the fibroblastic growth factor 23 (FGF23), is generally asymptomatic, except when the deficiency is very severe.

Case Description: A female patient undergoing bariatric surgery experienced, at an early stage

vitamin D deficiency with secondary hyperparathyroidism, and, ten and thirteen years after, develop two episodes of severe ferropenia, for which she was administered FeCXM. In both cases develop severe hypophosphatemia coursing in a completely asymptomatic.

Conclusions: Unless there is already a previous depletion of phosphorus, hypophosphataemia

secondary to FeCXM should not be an obstacle to future administrations. Reusing FeCXM should only be performed when phosphatemia values have recovered.
\end{abstract}

Volume 2 Issue I - 2015

\author{
Manuel Francisco Fernandez-Miera, Soledad \\ Gonzalez-Barrera, Iliana Pereda-Ugarte, \\ Aquilino Abad-Suero, Isabel Sampedro- \\ García, Carmen Escalada-Sarabia \\ Hospital de Dia Medico, Marques de Valdecilla University \\ Hospital, Spain
}

\begin{abstract}
Correspondence: Manuel F Fernandez Miera, Hospital de Dia Medico, Marques de Valdecilla University Hospital, B $^{\circ}$ Pozo de la Torre 8, Mortera-39I20, Cantabria, Spain, Tel 630056856,
\end{abstract} Emailmffmiera@terra.com

Received: April 20, 2015 | Published: May 15, 2015

Keywords: ferric carboxymaltose, hypophosphataemia, bariatric surgery

Abbrevations: FeCXM, ferric carboxymaltose; FeSCS, iron sucrose; FGF23, fibroblastic growth factor 23

\section{Text}

Hypophosphataemia is a rather common side effect after administration of ferric carboxymaltose (FeCXM); it has been also described, though less frequently and severely, after IV infusion of iron sucrose (FeSCS).1-3 In these cases, some studies have shown an excessive urinary phosphate loss mediated by the fibroblastic growth factor 23 (FGF23). ${ }^{4}$ It is generally asymptomatic, except when the deficiency is very severe (generally with serum phosphorus levels below $1 \mathrm{mg} / \mathrm{dL}){ }^{3,5}$ We report the case of a female patient with underlying concomitant diseases that promoted repeated occurrence of this condition, always asymptomatically.

A 28-year old female patient undergoing biliopancreatic by pass due to morbid obesity. Secondarily she experienced vitamin D deficiency with secondary hyperparathyroidism and underwent replacement therapy. At 38 years of age she was detected mild anaemia ( $\mathrm{Hb} 11.2 \mathrm{~g} / \mathrm{dL}$ ), but with severe ferropenia (ferritin $7 \mathrm{ng} / \mathrm{mL}$ ), for which she was administered 1,300 $\mathrm{mg}$ IV of FeCXM in two doses ( 800 and $500 \mathrm{mg}$ ) with a week in between. On the same date normal phosphataemia $(3.2 \mathrm{mg} / \mathrm{dL})$ was evidenced, and the other phosphoruscalcium metabolism parameters are shown in the table below. At 12 days of the first administration of FeCXM see Table 1, phosphataemia decreased to $1.3 \mathrm{mg} / \mathrm{dL}$. At 84 days (after receiving during that time three monthly doses of FeSCS $200 \mathrm{mg}$ ), her phosphataemia was still 2 $\mathrm{mg} / \mathrm{dL}$ see Table 1. At 162 days (after receiving during that time two monthly doses of FeSCS $200 \mathrm{mg}$ ) phosphorus had already returned to normal, to $3 \mathrm{mg} / \mathrm{dL}$ see Table 1 . Since then the patient received replacement therapy with Vitamin D IM weekly and oral calcium daily; she also visited monthly the Day Care hospital for laboratory tests and parenteral administration of trace elements, polyvitamins and calcium gluconate. At 41 years of age she was detected again mild anaemia ( $\mathrm{Hb} 11.9 \mathrm{~g} / \mathrm{dL}$ ) with severe ferropenia (ferritin $9 \mathrm{ng} /$ $\mathrm{mL}$ ) and was administered two doses of FeCXM 1,000 mg given 23 days apart. Phosphataemia was first $3.4 \mathrm{mg} / \mathrm{dL}$ see Table 1 . At 27 days of the first dose, these values had decreased to $1.3 \mathrm{mg} / \mathrm{dL}$ and at 55 days they had decreased even further, to $1.1 \mathrm{mg} / \mathrm{dL}$ see Table 1 . At 85 days phosphataemia had already returned to normal $(2.9 \mathrm{mg} / \mathrm{dL})$. There were no clinical signs of hypophosphataemia in any of the two episodes (proximal myopathy, rhabdomyolysis, respiratory and/or heart failure, arrhythmia, confusion, hallucinations, encephalopathy, seizures, etc.)

Except for very extreme cases, where there is already a general significant underlying phosphate reduction for other reasons. ${ }^{5}$ hypophosphataemia secondary to $\mathrm{FeCXM}$ is usually associated asymptomatic, so it should not prevent future administrations. However, in patients with previous phosphorus-calcium homeostasis disorders, as in the case of the patient reported herein, clinical and laboratory monitoring should be maximised for an early intervention. In addition, comparing the two hypophosphataemia episodes of our patient, it is very likely that the greater delay in the recovery from the first of them was due to the subsequent administration of FeSCS, 1,3 Therefore, once hypophosphataemia is detected, it does not appear to be advisable to use any of the two iron molecules until phosphataemia values have returned to normal. 
Table I Laboratory data

\begin{tabular}{|c|c|c|c|c|c|c|c|c|}
\hline \multirow{2}{*}{$\begin{array}{l}\text { Laboratory data } \\
\text { Day }\end{array}$} & \multicolumn{4}{|c|}{ Episode I } & \multicolumn{4}{|c|}{ Episode 2} \\
\hline & +0 & +12 & +84 & +162 & +0 & +27 & +55 & +85 \\
\hline Haemoglobin $(\mathrm{N}: \geq 12 \mathrm{~g} / \mathrm{dL})$ & 11.2 & 11.6 & 13 & 12.7 & 11.9 & 12.7 & 13 & 12.9 \\
\hline Ferritin (N: $|0-29| \mathrm{ng} / \mathrm{mL})$ & 7 & 485 & 270 & 232 & 9 & 179 & 328 & 216 \\
\hline Phosphorus (N: 2.5-4.5 mg/dL) & 3.2 & 1.3 & 2.0 & 3.0 & 3.4 & 1.3 & I.I & 2.9 \\
\hline Calcium Ion (N: I.I6-I.30 mM) & 1.20 & 1.23 & 1.19 & - & 1.29 & 1.23 & 1.22 & 1.26 \\
\hline Unchanged PTH (N: 10-45 pg/mL) & 89 & 60 & 94 & - & 49 & 133 & 81 & 53 \\
\hline 25-OH-Vitamin D (N: $20-60 \mathrm{ng} / \mathrm{mL})$ & 12 & 37 & 19 & - & 31 & 38 & 43 & 46 \\
\hline
\end{tabular}

Abbreviations: N, normal values; PTH, para thyroid hormone

\section{Acknowledgments}

None.

\section{Conflict of interest}

Collaboration with Laboratorios Vifor Pharma participating in a "Roundtable with the expert: MANAGEMENT OF IV IRON THERAPY FROM THE DAY HOSPITAL. EFFICIENCY MODELS" during the $35^{\text {th }}$ National Congress of the Spanish Society of Internal Medicine.

\section{References}

1. Hayat A. Safety issues with intravenous iron products in the management of anemia in chronic kidney disease. Clin Med Res. 2008; 6(34):93-102.
2. Van Wyck DB, Mangione A, Morrison J, et al. Large-dose intravenous ferric carboxymaltose injection for iron deficiency anemia in heavy uterine bleeding: a randomized, controlled trial. Transfusion. 2009;49(12):2719-2728.

3. Blazevic A, Hunze J, Boots JM. Severe hypophosphataemia after intravenous iron administration. Neth J Med. 2014;72(1):49-53.

4. Wolf M, Koch TA, Bregman DB. Effects of iron deficiency anemia and its treatment on fibroblast growth factor 23 and phosphate homeostasis in women. J Bone Miner Res. 2013;28(8):1793-1803.

5. Fierz YC, Kenmeni R, Gonthier A, et al. Severe and prolonged hypophosphatemia after intravenous iron administration in a malnourished patient. Eur J Clin Nutr. 2014;68(4):531-533. 